\title{
Health, economic and social lifestyle: a rapid assessment of COVID-19: evidence from MENA countries
}

\author{
Taha Almarayeh \\ American University of Madaba, Madaba, Jordan, and \\ Abdulateef Almarayeh \\ Universidade de Santiago de Compostela - Campus de Santiago, \\ Santiago de Compostela, Spain
}

\begin{abstract}
Purpose - Middle Eastern and North African (MENA) countries are among the most affected regions globally, which are expected also to be influenced significantly for an extended period. This paper aims to consider an attempt for a real-time evaluation of the colossal impact of the coronavirus (COVID-19) pandemic on health, economic and social sectors in MENA nations.

Design/methodology/approach - This paper draws from published academic studies. It is also based on the synthesis of news broadcasted and current media sources, government speeches and reports, as the novel COVID-19 situation is unfolding. The authors' experiences investigating in this domain have also contributed to the research.

Findings - This investigation captures events on the novel COVID-19, as they are unfolding now. The study predicts that the COVID-19 pandemic will probably affect the general patterns of MENA people's lifestyles. In addition, the COVID-19 epidemic will have a substantial influence on healthcare systems and economic sectors in MENA countries.

Research limitations/implications - This viewpoint paper offers some emerging outlooks, appearing with the contemporary novel COVID-19 outbreak. This study provides valuable insights to inform investors, policymakers and the public that natural disasters can inflict economic damage on an unprecedented scale.

Originality/value - This is a "real-time" evaluation study. To the best of the authors' knowledge, this is the first study that map and assess the potential impacts of COVID-19 pandemic on health-care systems, economic sectors and people's lifestyle in MENA countries.
\end{abstract}

Keywords MENA countries, Economic impact, Health system, Coronavirus, COVID-19

Paper type Viewpoint

\section{Introduction}

On February 11, 2020, the World Health Organization (WHO) formally declared the first cases of a new coronavirus (COVID-19) disease. In late December 2019, China reported the

(C) Taha Almarayeh and Abdulateef Almarayeh. Published in PSU Research Review. Published by Emerald Publishing Limited. This article is published under the Creative Commons Attribution (CC BY 4.0) licence. Anyone may reproduce, distribute, translate and create derivative works of this article (for both commercial and non-commercial purposes), subject to full attribution to the original publication and authors. The full terms of this licence maybe seen at http://creativecommons.org/licences/by/4.0/legalcode

The author gratefully acknowledges that there is no funding to support this research paper.

Received 19 January 2021 Revised 14 March 2021 Accepted 16 April 2021 
first fatalities in early 2020. The high infection rates and death led the Chinese Government to quarantine Wuhan's city on January 23, 2020. During this duration, many nations began, consequently were announcing their first confirmed cases of the disease. On January 30, 2020, WHO announced an International Public Health Emergency before the formal declaration of the COVID-19 as an outbreak pandemic [1]. Up the time of this writing, 57,709,397 million cases have been recorded in 191 nations, with 1,374,824 total deaths and 40 million cases are reported to have recovered [2]. These numbers are anticipated to have risen significantly before the publication of this paper. The most firmly harmed areas were the USA, Brazil and Europe. WHO is still working hard to set up a research lab's collaborative network to find a successful serum. Besides, WHO summarized the disease symptoms: if any patient with severe acute respiratory symptoms (fever, sore throat, cough, muscle pain and shortness of breath), with a history of connection to endemic regions of COVID-19 or contact with an infected person over the past 14 days [3].

According to WHO, the virus has spread to most developing countries such as Middle Eastern and North African (MENA) countries. Unfortunately, these countries have acquired novel COVID-19 through people who have returned from endemic areas. As an attempt to limit the risk of COVID-19 transmission, the governments of endemic countries have implemented several preventative measures. In particular, the governments have recommended that all people should wear face masks and wash hands vigorously using liquid soap. However, some precautionary measures now affect the daily routines of millions of people worldwide. For example, "social distancing" considers the most widely used, which endeavors to curtail new infections by lessening physical touch between people. As a result, most events and conferences were canceled, schools and colleges were closed. Further, the economic cycle has been stopped. With this situation, numerous economic activities have been influenced, such as business and trading, transportation, tourism, service delivery, retail sales and production and manufacturing because there are no peaceful environment, technologies and infrastructure to permit a remote workplace. This article is one of the first academic publications aimed at providing a brief analysis and evaluation of the enormous economic, health and social impact of COVID-19 in MENA countries. This paper is anticipatory, sketching the scant research yet, on COVID-19 pandemic and social, economic implications. This paper can be seen as a "real-time evaluation." It presents insights and snapshots for all related stakeholders and decisionmakers to understand the current situation mainly at the national level. This manuscript draws from published academic studies. It is also based on the synthesis of news broadcasted and current media sources, government speeches and reports, as the novel COVID-19 situation is unfolding. The authors' experiences investigating in this domain have also contributed to the research.

The remainder of the article is organized as follows. Section 2 discusses the spread of COVID-19 in MENA countries. Section 3 shows the health implication of COVID-19 in MENA countries, where Section 4 summarizes the effect of COVID-19 on individual aspects of the MENA economy. Section 5 explains the influence of COVID-19 on people's lifestyles. Then the article concludes with implications, limitations and future research directions in Section 6.

\section{Spread of COVID-19 in Middle Eastern and North African countries}

As a small village, no area in the world is isolated from what is happening, especially with global diseases. Countries across the Arab region are recording many COVID-19 cases of infection. The first case of the deadly COVID-19 in the MENA was reported on January 29, 2020, in the United Arab Emirates [4]. From mid-February 2020, several MENA countries 
have experienced a significant rise in confirmed cases, such as Egypt, Algeria, Lebanon and Gulf countries. The COVID-19 pandemic has also continued to spread to other MENA countries. On March 2, 2020, the first cases in Saudi Arabia, Tunis, Morocco and Jordan were confirmed. Other MENA nations were slightly late reporting such suspected cases such as Syria, Mauritania, Sudan, Somalia, Djibouti and Libya. The primary analysis shows that most of the identified cases are mainly obtained through people who have returned from outside countries such as Europe, the USA and China.

\section{The health system in Middle Eastern and North African and COVID-19 consequences}

Despite the great medical efforts over the entire world, no clear signs records show COVID19 abating out of China Republic. On the other hand, according to the WHO, developing a new COVID-19 vaccine may take 12 to 18 months. Due to many MENA countries coping with the rampant civil war, revolution and fear, the health-care system may not face such challenges to provide suitable healthy for their patients. There are growing concerns about the probability of an outbreak in MENA countries, which, in turn, could lead to a perfect storm as a worst-case scenario in this century. In particular, several MENA countries' health-care infrastructure suffers from a sharp shortage of medical facilities to deal with this outbreak. Indeed, the health-care sector is already overwhelmed because of continuous unrest. There is a limited number of quarantine rooms, personal protective equipment, ambulances equipped, facemasks, simple hygiene preparations - hand sanitizers and disinfectants - and trained staff. Another real hurdle is facing MENA, represented by the shortage of COVID-19 tests. Besides, there is a low degree of awareness in the community concerning disease prevention, such as avoiding congested areas and shaking hands. Hence, this situation will inevitably affect the spreading of the COVID-19 virus. Meanwhile, even wealthy countries (i.e. Gulf States) characterized by equipped and strong health-care systems are still facing problems to control such rapid spreading viral infections. Many states follow the Chinese procedure as an immediate measure by imposing a quarantine on their population. Nevertheless, such a process may affect other dimensions, especially those related to isolated patients' health.

The quarantine may change lifestyles, causing significant stress and anxiety, worsening depression of loneliness and adverse effects on glycemic and blood pressure. In addition, the demand for health-care services will increase due to the limited opportunities in appointments with primary care physicians and cardiologists.

Up the time of this writing, the fear of a second wave is rapidly increased to strike again in MENA countries and the entire world. Such expectations have already happened as in Palestine, which regained the quarantine's enforcement and went back to the first square. Table 1 shows COVID-19 statistics in MENA countries arranged according to the most recorded cases (confirmed and death).

\section{The economic impacts}

The pandemic of COVID 19-to date causes vast harm to peoples' physical and mental health, as well as to their economy. COVID 19 paralyzed the entire world, drives it to be at home arrest and forces it to make cruel decisions that will undoubtedly inevitably affect the economy and the previously established plans. As a part of this world, MENA states are not immune or an exception to what is happening globally. The expectations regarding their budgets after this crisis turned upside down with deficits in varying proportions.

Besides the contagious nature of COVID-19, which spilled over to other countries, the adverse effects also spilled over to the global value chains economically to countries, 


\section{PRR}

Table 1.

COVID-19 Statistics (as at November 21,

\begin{tabular}{rlrrrrrr}
\hline Num & Country & Total cases & New cases & Total deaths & Total recovered & Active cases & Population \\
\hline 1 & World & $58,065,609$ & 166,615 & $1,380,575$ & $40,243,778$ & $16,441,256$ & \\
2 & Iraq & 533,555 & 1,786 & 11,925 & 463,040 & 58,590 & $40,568,064$ \\
3 & Saudi Arabia & 355,034 & 221 & 5,761 & 342,882 & 6,391 & $35,023,049$ \\
4 & Morocco & 316,260 & & 5,182 & 262,212 & 48,866 & $37,080,030$ \\
5 & Egypt & 112,318 & & 6,521 & 101,685 & 4,112 & $103,076,366$ \\
6 & Jordan & 174,335 & & 2,116 & 103,834 & 68,385 & $10,242,451$ \\
7 & UAE & 157,785 & 1,262 & 548 & 148,080 & 9,157 & $9,936,680$ \\
8 & Kuwait & 139,734 & 426 & 863 & 131,560 & 7,311 & $4,294,959$ \\
9 & Qatar & 137,062 & 174 & 235 & 134,100 & 2,727 & $2,807,805$ \\
10 & Oman & 121,360 & & 1,365 & 112,406 & 7,589 & $5,156,180$ \\
11 & Lebanon & 113,655 & & 884 & 64,685 & 48,086 & $6,813,410$ \\
12 & Tunisia & 86,265 & & 2,684 & 60,486 & 23,095 & $11,866,594$ \\
13 & Bahrain & 85,467 & & 338 & 83,416 & 1,713 & $1,723,896$ \\
14 & Libya & 76,808 & & 1,068 & 47,587 & 28,153 & $6,907,419$ \\
15 & Algeria & 72,755 & & 2,236 & 47,581 & 22,938 & $44,155,708$ \\
16 & Palestine & 70,254 & 1,486 & 620 & 58,383 & 11,251 & $5,146,776$ \\
17 & Sudan & 15,530 & & 1,185 & 9,682 & 4,663 & $44,240,835$ \\
18 & Mauritania & 8,075 & & 169 & 7,560 & 346 & $4,696,245$ \\
19 & Syria & 7,079 & & 368 & 2,986 & 3,725 & $17,663,082$ \\
20 & Djibouti & 5,660 & & 61 & 5,551 & 48 & 993,549 \\
21 & Yemen & 2,090 & & 608 & 1,434 & 48 & $30,077,585$
\end{tabular}

Source: www.worldometers.info

which have more than half of world supply and demand is accounted for and also have the most recorded cases of COVID-19 such as China, Korea, Italy, Japan, the USA and Germany.

According to ESCWA (2020), the preliminary estimates suggest that the Arab region could lose US $\$ 42 \mathrm{bn}$ of gross domestic product (GDP). Which, in turn, could increase the unemployment rate by 1.2 percentage points. Besides, the area could lose at least 1.7 million jobs in 2020. Indeed, the influence of COVID-19 relies upon many factors as the seriousness of COVID-19, the span of COVID-19 and the composition of an economy, especially the significance of service industries in GDP.

COVID-19 has a massive influence on many sectors. Due to the spread of COVID-19, community movement was restrained. Families lessened their consumption-demand for food, clothes, travel and entertainment- and the number of guests in hotels have faded sharply, as well as the public transportation, retail outlets, hotels and restaurants. At the heart of this dilemma, the tourism and oil industries in the Arab area represent the crucial contributors to the economy. COVID-19 destroys the Arab tourism industry. The cancellations of flights by domestic and international airline firms from and to Arab countries have affected their revenues. As a response to the COVID-19 threat, many Arab nations are implementing emergency measures to mitigate the expected adverse economic and social implications for people and businesses. Arab Governments have already put in place alleviation propositions. For example, the United Arab Emirates announced a US $\$ 27 \mathrm{bn}$ stimulus plan.

Furthermore, Qatar, Saudi Arabia and Egypt announced a similar package of US\$23bn, US\$13bn and US\$6, respectively. Besides, Jordan announced a similar package to combat the spreading virus and support economic growth. COVID-19 is a genuinely global crisis, and all will feel its financial implications in an endeavor to understand the turmoil impact on 
the economy. We broadly summarize the influence of COVID-19 on individual aspects of the MENA economy countries.

\subsection{Oil}

Regarding the oil sector and since 1990, oil prices have registered the hardest cut-off in one single day; the crude oil price plunged with more than 20\% (Albulescu, 2020). Albulescu (2020) argues that the crash of oil prices reveals that an economic downturn cannot be avoided. The current decline in oil demand is affected by constraint and containment procedures in many countries (Aloui et al., 2020). Nevertheless, the historic oil price collapse is an opportunity for others, such as lower-cost producers, to regain market share. A leeway could be offered for MENA oil imports by exploiting such a price drop, but their economic challenge lies in the remittance inflows and foreign direct investments besides the weak demand for goods and services from the rest of the region. Such a scenario will make many countries in MENA suffer from huge deficits to their budget due to unexpected prices making their economic growth severely affected. Figure 1 exhibits the direct impact of the oil price collapse in the countries' real income (per cent of GDP change).

\subsection{Agriculture}

Agriculture is one of the essential sectors in human development, which is related to food security (Kogo et al., 2021; Lopez-Ridaura et al., 2019). According to Siche (2020), the agricultural sector highly contributes to the sustainability, growth and development of the economy in the MENA. The Food and Agriculture Organization (FAO, 2020) states that COVID-2019 is affecting the supply and demand for food. About $20 \%$ of the agricultural products' price has dropped globally (Jayashree, 2020). Due to self-isolation tips, several sectors will be affected, such as inspectors and delivery staff "mobility restrictions" who keep an eye on verification and transportation of products, raising some fears about some perishable goods.

\subsection{Bank}

As one of the most supportive sectors to any country's incomes, which also organizes people's financial operations as mediators with either their public or private institutions,

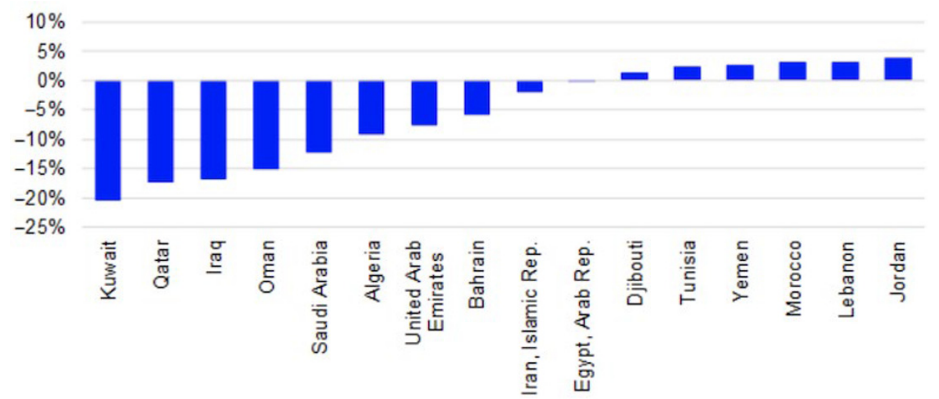

Note: This estimation is based on the hypothetical assumption that oil prices will stay $48 \%$ below the 2019 level

Source: Graph extracted from the World Bank: Coping with a Dual Shock: covid-19-and-oil-prices

Figure 1. Estimating the direct impact of the oil price collapse in the countries' real income ( $\%$ of GDP change) 
banks and insurance sectors still have the highest and most extended exposure to credit risk because of the pandemic. Prior studies show that a higher risk of a general banking collapse, as the joint prevalence of large pandemics increases as in Lagoarde-Segot and Leoni (2013).

The current novel, COVID-19 pandemic, continues to affect every single financial institution negatively. Ozili and Arun (2020) indicate that COVID-19 raises the percentage of nonperforming loans from those issued to small-medium scale enterprises, airlines, hotels, tour operators, restaurants, retail, construction and real estate businesses. COVID-19 has decreased the volume of bank transactions, a decline in card payments and a fall in the use of automated teller machine cash machines worldwide, leading to fewer fees collected by banks, which negatively affected banks' profit.

\subsection{Education}

The crisis compels great challenges that the education sector has to face. According to UNESCO (2020), figures that nearly all education institution's closure affects about $1,186,161,728$ students in more than 146 countries.

New teaching methods for the first time in many MENA countries are used. Online education is the stage champ for many MENA universities during the campus closure, taking into account the variation of their abilities in achieving excellent e-learning. Some applications are used to support, ease and deliver online courses that involve Blackboard, Moodle, email and Zoom. Such tools were well-known before the crisis; however, the crisis has accelerated the strategies to benefit from them (Crawford et al., 2020).

Developing countries as MENA face many obstacles regarding distance learning during the COVID-19 pandemic. Many studies show the psychological effect for most pupils who are not comfortable with the remote learning experience and sustainable education (Khoshaim et al., 2020). Most pupils suffered from some limitations as the internet's speed and its area coverage, the absence of stimulation and distractions such as games. However, the agreed social fact for both parents and students is that the conventional education style is more valuable than the remote learning style. Nevertheless, it is crucially essential to notice that distance learning is the safest available means to ensure learning continuity in educational institutes during this crisis (Bataineh et al., 2021). However, accuracy must be taken in adopting statistics until they are formally approved at the beginning of the crisis, in this context, Sundarasen et al. (2020) say that the students' anxiety levels could not have been the same where most of the data had been gathered during the peak period COVID-19 pandemic, which was at the beginning of 2020 Spring. Many articles were not possible to be published as their authors had to wait for ethical approvals from the relevant authorizations.

In a recent study about learning in some MENA countries (Egypt, Iraq, Palestine, etc.), Lassoued et al. (2020) say that distance (remote) learning has become an essential requirement for higher education institutes (universities), required by the status of crisis conditions in which all over the world lives. As a response to the reflex for a current education policy that mixes technology and designs flexibility in the education scene to reach educational safety and develop university outcomes. They conclude (taking into consideration the country's ability, especially the economic sector) to achieve distance learning's quality for the studied area and other neighbors' areas by rethinking in better schools and collages support by providing them with computer labs and training teachers and students alike on the optimal usage of recent interaction technologies. The need for coordination between wealthy Arab countries (Gulf States) and the poor ones is a necessary requirement that for sure considers a great solution in improving remote education, particularly concerning electronic school and college curricula and distance testing. 
Widespread socioeconomic implications accompanied this crisis, its procedures of prevention, the social movement and the financial onus for many families, especially whose children "pupils" benefit from their schools' free meals. The wide inequality among communities with high and low salaries is always a distinguishing factor, especially in accessing technology to ensure learning continues digitally during social isolation.

\subsection{Tourism}

The tourism sector considers as one of the worst-affected of economy parts by the COVID-19 crisis. Many experts think that the shock to the industry of global tourism could range to $45 \%-70 \%$ of output as initial reports depending on the pandemic lasting (OECD, 2020). Numerous countries, including the MENA nations, are using targeted proposals to promote their tourism industry. The containment procedures and the shock of economic growth in countries such as China, the USA and the European Union will further decrease tourist visitors to the Middle East. Such a slump in tourism movement is anticipated to have a notable influence in many countries in the MENA region and the entire world, mainly those relying heavily on tourism as an origin of income, notably Jordan, UAE, Lebanon and Egypt. In Egypt, where the tourism sector provides near to 12\% of GDP (OECD, 2020).

Regarding tourism from China and Southeast Asia countries, COVID-19 possibly diminishes tourism from them to MENA in several ways, beginning with the attraction factor where many MENA countries are now requiring travel constraints on Chinese people. Saudi Arabia pended the door of pilgrims to religious places, decreasing tourism to/from the Gulf and the Middle East countries. Second, what is called by the experts of tourism "the push factor:" the slowdown of the Chinese economy signifies fewer tourists traveling to other parts of the world, including MENA countries. The Pacific region and East Asia are likely to witness the most acute decline in Chinese tourists. The tourist arrivals to MENA are assumed to be more limited.

\section{Social effect}

The impact of COVID19 on personal and social gatherings has been sharp due to medical specialists' recommendations. Local governments often mandated "stay-at-home" orders to limit meetings in any number. Such arrangements may be substituted by teleconferencing or in some situations with alternate attempts to control social distancing with activities such as a "birthday parade" for a birthday party or "balcony sing-along" for a concert. Here we review the most prominent reactions and efforts taken by states and organizations concerning MENA religious, cultural and social rituals.

The International Union of Muslim Scholars, and according to the Secretary-General Ali Qara Daghi, issued "Fatwa" that it is permissible to temporarily prevent the practice of "Umrah and Hajj" rituals if the COVID-19 epidemic breaks out categorically. Most people think that pilgrims or some of them may become infected with the pandemic due to crowding. Dealing with such a pandemic is very hard for millions of Muslims' feelings who are used to visit both Medina and Mecca, especially during Ramadan month; it is also very harsh to see "AL haram" mosque in Saudi Arabia almost empty of its goers, which could be a historical precedent has not been witnessed by many generations.

The situation is the same for many mosques and churches among many MENA countries. Iraq state and Kurdistan region and many states such as Jordan, Egypt, Iran, Tajikistan and others, have declared to prevent for a limited time the Friday pray, as procedures to limit the spread of COVID-19. Many countries prevent going to mosques and churches for a certain unknown time, although some of these countries, such as Tajikistan, has not recorded any COVID-19 state. 
In many MENA countries, religious rituals have very strong connections with cultural and social life events. Many Muslims were forced to celebrate Ramadan's holy month among their own little family away from their relatives; as usual, the gatherings were within few people among the same building. Such pandemic imposed new food customs where the house kitchen food took his role again away from the ready junk food. It is better to mention the meeting habits between the people of many MENA countries, starting with handshaking, cheek face kisses and hugs as means of yearning to the others, love and respect to the community members, particularly in public events such as marriage celebrations and burials. Many of these habits have disappeared or reduced to be just by handshaking or sending regard or condolences by calling or messages.

Regarding the internal relationships, many family members have tested their links with each other for being staying in the same environment for a long time, the husband with his wife and his children, the elder with the younger. The corporation's spirit was a challenge during the prevent roaming, which varies according to every state situation. Schoolchildren were not away from these crises, away from the direct connection with their teachers, friends and schools. For keeping them in touch with their education, many MENA countries experienced remote learning as an alternate solution; nevertheless, it was an extra challenge for many parents to keep up with such an experience, as the majority of MENA families have two or more schoolchildren, some of them have six and even more. In the past two decades, the MENA people's confidence in the local media was questionable and avoided by many viewers for many reasons either by comparing it with the global media and their qualities or the disregard due to social media and its widespread in the entire world. In contrast and during the pandemic, the official television was a reliable source for knowing the COVID-19 state in a particular nation, waiting for the government spokesperson to declare the number of victims daily.

\section{Conclusion}

There is no doubt that people across the globe have been denied their rights to access these services due to political and commercial decisions. As we have seen, such rights manifest in a wide diversity of ways across the health care, business and tourism environment. The purpose of this study is to provide a rapid assessment of the social, healthy and economic implications of the COVID-19 pandemic in MENA countries. This perspective article takes the MENA countries as a case in point to discuss the effects of COVID-19 on their lifestyle choices, the health system and economic implications. This study shows that the COVID-19 pandemic spillover into MENA countries caused new shocks in their economics.

Consequently, the economic crisis's scope and severity have clearly affected the growth and development reforms in these nations. Swift attention is needed from MENA Governments to organize and unify measures at the macro and micro levels based on a broad and inclusive path that leaves no one behind. Our work presents critical insights to inform investors, policymakers and the public that natural disasters can unprecedentedly inflict economic damage that has not been witnessed before. Besides, it presents an overview and initial assessment of the effect of COVID-19 in the MENA area.

This manuscript has limited its nature. We perceive that any such research is constrained by precisely when it is written in the setting of quickly moving worldwide events. A future research line would be to consider more the sociological and psychological impacts will be more enduring. It would probably be interesting to navigate the current post-COVID-19 scene carefully and compassionately. More works are likely needed to 
evaluate and analyze the efficiency of governmental responses to COVID-19 in developing countries such as MENA nations. Further, a future research line would probably be appealing to investigate how the MENA equity markets react to the progress of infection and death rates from COVID-19.

\section{Notes}

1. See the WHO Director-General's opening remarks at the media briefing on COVID-19 on March 11, 2020, available at: www.who.int/dg/speeches/detail/who-director-general-s-opening-remarksat-the-media-briefing-on-covid-19\%E2\%80\%9411-march-2020 (accessed 10 June 2020).

2. See also the COVID-19 map for an update (available at: https://coronavirus.jhu.edu/map.html (accessed August 25, 2020).

3. See WHO, Clinical management of severe acute respiratory infection when novel COVID-19 $(2019-\mathrm{nCoV})$ infection is suspected. Interim guidance, available at: www.who.int/docs/defaultsource/coronaviruse/clinical-management-of-novel-cov.pdf (accessed 25 August 2020).

4. See also the COVID-19 map for an update (available at: https://coronavirus.jhu.edu/map.html, (accessed 25 August 2020).

\section{References}

Albulescu, C. (2020), "Coronavirus and oil price crash", available at: SSRN 3553452.

Aloui, D., Goutte, S., Guesmi, K. and Hchaichi, R. (2020), "COVID 19's impact on crude oil and natural gas S\&P GS indexes”, available at: SSRN 3587740.

Bataineh, K.B., Atoum, M.S., Alsmadi, L.A. and Shikhali, M. (2021), "A silver lining of coronavirus: Jordanian universities turn to distance education", International Journal of Information and Communication Technology Education (IJICTE), Vol. 17 No. 2, pp. 1-11.

Crawford, J., Butler-Henderson, K., Rudolph, J. and Glowatz, M. (2020), "COVID-19: 20 countries' higher education intra-period digital pedagogy responses", Journal of Applied Teaching and Learning (JALT), Vol. 3 No. 1.

ESCWA (2020), Economic Cost to the Arab Region, available at: www.unescwa.org/sites/www. unescwa.org/files/escwa-covid-19-economic-cost-arab-region-en.pdf

FAO (2020), "Food and agriculture organization. Q\&A: COVID-19 pandemic - impact on food and agriculture", available at: www.fao.org/2019-ncov/q-and-a/en/

Jayashree, B. (2020), "Prices of agricultural commodities drop 20\% post COVID-19 outbreak", available at: http://economictimes.indiatimes.comhttps:/economictimes.indiatimes.com/news/economy/ agriculture/prices-of-agricultural-commodities-drop-20-post-covid-19-utbreak/printarticle/74705 537.cms?utm_source $=$ contentofinterest\&utm_medium $=$ text\&utm_campaign $=$ cppst

Khoshaim, H.B., Al-Sukayt, A., Chinna, K., Nurunnabi, M., Sundarasen, S., Kamaludin, K., Baloch, G.M. and Hossain, S.F.A. (2020), "Anxiety level of university students during COVID-19 in Saudi Arabia”, Frontiers in Psychiatry, Vol. 11, p. 1397.

Kogo, B.K., Kumar, L. and Koech, R. (2021), "Climate change and variability in Kenya: a review of impacts on agriculture and food security", Environment, Development and Sustainability, p. 1-21.

Lagoarde-Segot, T. and Leoni, P.L. (2013), "Pandemics of the poor and banking stability", Journal of Banking and Finance, Vol. 37 No. 11, pp. 4574-4583.

Lassoued, Z., Alhendawi, M. and Bashitialshaaer, R. (2020), "An exploratory study of the obstacles for achieving quality in distance learning during the COVID-19 pandemic", Education Sciences, Vol. 10 No. 9, p. 232. 
Lopez-Ridaura, S., Barba-Escoto, L., Reyna, C., Hellin, J., Gerard, B. and van Wijk, M. (2019), "Food security and agriculture in the Western Highlands of Guatemala", Food Security, Vol. 11 No. 4, pp. 817-833.

OECD (2020), "Organisation for economic Co-operation and development: COVID-19 crisis response in MENA", available at: www.oecd.org/coronavirus/policy-responses/covid-19-crisis-response-inmena-countries-4b366396/\#back-endnotea0z25.

Ozili, P.K. and Arun, T. (2020), "Spillover of COVID-19: impact on the global economy", available at: SSRN 3562570.

Siche, R. (2020), "What is the impact of COVID-19 disease on agriculture?", Scientia Agropecuaria, Vol. 11 No. 1, pp. 3-6.

Sundarasen, S., Chinna, K., Kamaludin, K., Nurunnabi, M., Baloch, G.M., Khoshaim, H.B., Hossain, S.F. A. and Sukayt, A. (2020), "Psychological impact of COVID-19 and lockdown among university students in Malaysia: implications and policy recommendations", International Journal of Environmental Research and Public Health, Vol. 17 No. 17, p. 6206.

UNESCO (2020), “COVID-19 educational disruption and response”, available at: https://en.unesco.org/ covid19/educationresponse.

\section{Corresponding author}

Taha Almarayeh can be contacted at: taha.marayeh@gmail.com

For instructions on how to order reprints of this article, please visit our website: 